by the madness of mobs. Will a crowdsourced scholarship be dominated by provocative pap that fills without nourishing?

Here we must recall first that scholarship has always been a community enterprise, driven by building consensus among experts ${ }^{10}$. So the question is not 'Should we crowdsource?' but 'How should we crowdsource?'. Second, we must dispose of the straw-man argument that hundreds of uninformed readers' opinions will count for more than one Fields medallist's recommendation. Authority and expertise are central in the Web era as they were in the journal era. The difference is that whereas the paperbased system used subjective criteria to identify authoritative voices, the Webbased one assesses authority recursively from the entire community.

We now have a unique opportunity as scholars to guide the evolution of our tools in directions that honour our values and benefit our communities. Here's what to do. First, try new things: publish new kinds of products, share them in new places and brag about them using new metrics. Intellectual playfulness is a core scholarly virtue. Second, take risks (another scholarly virtue): publishing more papers may be safe, but scholars who establish early leadership in Webnative production will be ahead of the curve as these genres become dominant. Finally, resist the urge to cling to the trappings of scientific excellence rather than excellence itself. 'Publication' is just one mode of making public and one way of validating scholarly excellence. It is time to embrace the Web's power to disseminate and filter scholarship more broadly and meaningfully. Welcome to the next era of scholarly communication.

Jason Priem is an information scientist at the University of North Carolina at Chapel Hill, North Carolina, USA, and co-founder of ImpactStory. e-mail:jason@impactstory.org

1. Priem, J., Costello, K. \& Dzuba, T. figshare http://doi.org/kvx (2012).

2. Cronin, B. J. Inform. Sci. 27, 1-7 (2001).

3. Priem, J. \& Hemminger, B. H. Front. Comput. Neurosci. 6, 19 (2012).

4. Smith, J. W. T. Learn. Publ. 12, 79-91 (1999).

5. Esposito, J. J. J. Electron. Publ. http://dx.doi. org/10.3998/3336451.0011.203 (2008).

6. Piwowar, H. Nature 493, 159 (2013).

7. Wilhite, A. W. \& Fong, E. A. Science 335 , 542-543 (2012).

8. Priem, J. \& Hemminger, B. M. First Monday (5 July 2010).

9. Edelman, B. G. \& Larkin, I. Harvard Business School NOM Unit Working Paper No. 09-096 (2009)

10.Kuhn, T. S. The Structure of Scientific Revolutions (Univ. Chicago Press, 1962).

The author declares competing financial interests: see go.nature.com/szgqx9 for details.

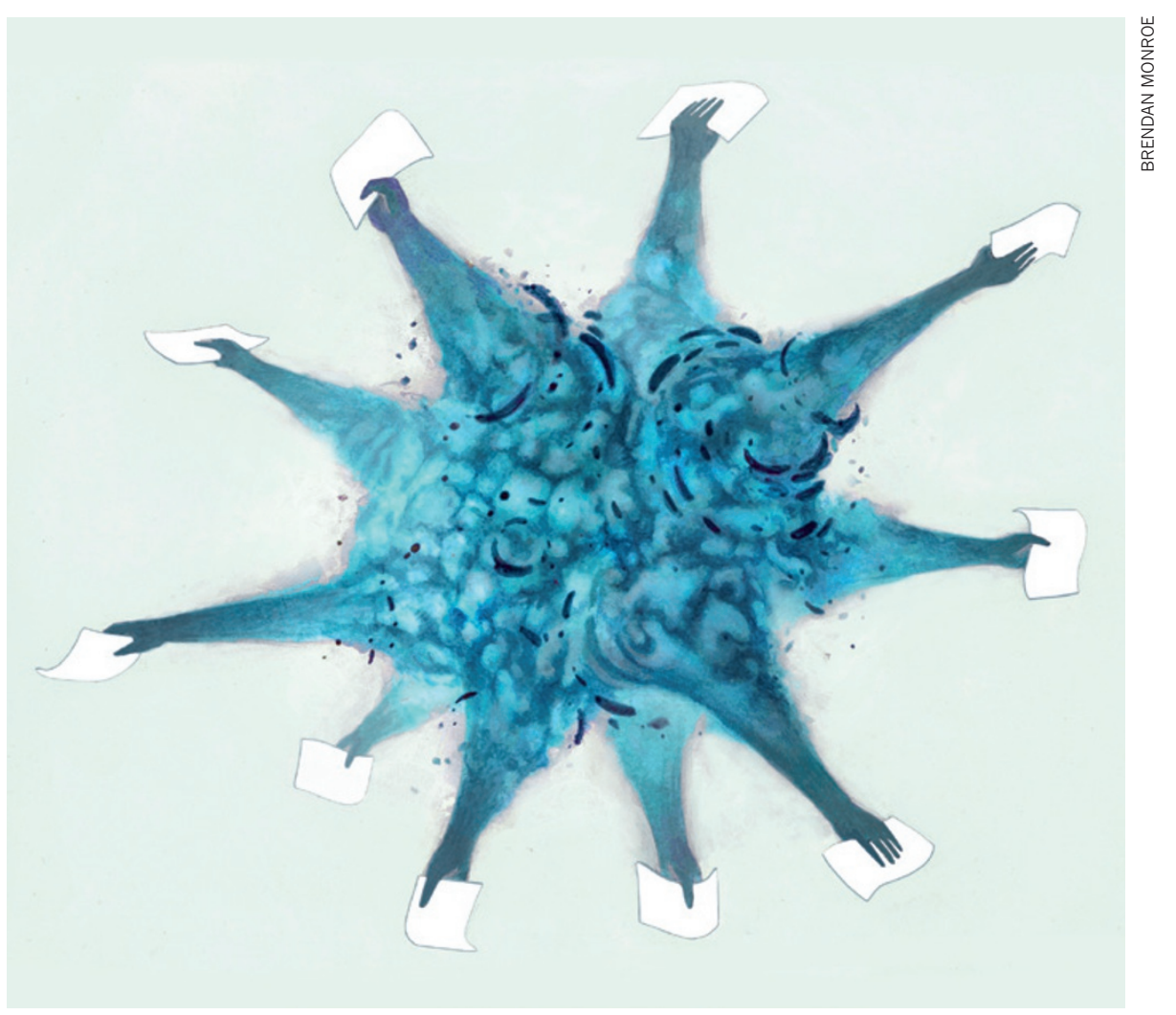

\title{
A fool's errand
}

\section{Objections to the Creative Commons attribution licence are straw men raised by parties who want open access to be as closed as possible, warns John Wilbanks.}

C opyright licensing is a topic usually left to law review articles, or obscure terms of service on websites, or agreements between publishers and libraries. But it is an essential element of the move towards open access - the free, immediate online availability of scholarly articles coupled with the right to use them fully in the digital environment.

An article that is free to read is not necessarily open for all uses - often, it cannot be reused for text mining or in derivative works, for example. The permitted uses depend on the copyright licence used by the author.

In my view, for an article to be considered truely open access, it has to meet the widely accepted definition in the Budapest Open Access Initiative - a set of recommendations laid out by leaders of the open-access movement in 2001. That is, users must be able to "read, download, copy, distribute,

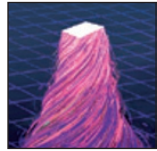

THE FUTURE OF PUBLISHNG A Nature special issue. nature.com/scipublishing print, search, or link to the full texts of these articles, crawl them for indexing, pass them as data to software, or use them for any other lawful purpose without financial, legal, or technical barriers other than those inseparable from gaining access to the internet itself. The only constraint on reproduction and distribution, and the only role for copyright in this domain, should be to give authors control over the integrity of their work and the right to be properly acknowledged and cited."

Traditional publishing licences tend to place restrictions on at least one of these uses, and it isn't easy for a reader to figure out what those are. If the reader is a computer, as is more and more prevalent, the restrictions are a spanner in the works.

The use of the Creative Commons attribution licence (CC-BY) fulfils the community definition of open access and avoids a future morass of articles with murky legal provenance and concomitant unclear reuse possibilities. CC-BY was launched in 2002, 2 years before I started a 7 -year stint as head of science initiatives at Creative Commons in 
Mountain View, California.

CC-BY has now come under attack from the International Association of Scientific, Technical \& Medical Publishers, which is discussing the introduction of a licence that would implement some - but not all — of the commonly accepted tenets of open access. At a conference run by the association in January, this was referred to variously as a "new" licence and even as "CC Plus".

It is a bad idea. Here's why.

\section{TRIED AND TRUE}

CC-BY is a liberal licence that allows any kind of use under copyright as long as the author is credited in the manner in which he or she specifies. It is more than a decade old, clear, well-tested and deeply established as an effective open-access licence for both for-profit and non-profit publishers (see 'Licence to share'). It has been translated into more than 50 languages and is legally enforceable around the world. No other open-access licence can claim its power, standing and adoption.

Critics have lately dubbed CC-BY 'viral', and bridled against the idea of research councils mandating its use as a way to implement open access for the scholarly literature. 'Viral' can be read either in the cultural sense - an article becoming wildly popular - or in the legal sense. The former is desirable. The latter is false: CC-BY does not force derivative works to be relicensed under the same terms.

Nor is it an unprecedented act for a funder to maximize its return on investment by specifying that publications arising from its funds be published under a liberal copyright licence. Taking money for research comes with conditions: grants from the US National Institutes of Health, for example, come with more than 70 such requirements, including data-sharing plans, annual reports, ethics training and gender indicators. That one of those conditions be intended to optimize a research article's impact by enabling its reuse by other researchers, their robots or by entrepreneurs, sits well within the funding tradition.

Any licence that is less open than CC-BY reserves the rights of the copyright holder to control certain reuses, and that requires a legitimate justification. If an article's publication costs have been covered by an articleprocessing fee, then reserving rights is just a means of double dipping.

Furthermore, funders who want the maximum impact are going to choose an existing standard legal tool that is interoperable with the vast majority of free culture and free software licences, not bet on a licence that might not be. Licences that distinguish between kinds of reuse, or discriminate against entrepreneurs, fail every definition of open access, open knowledge and open source. Tiny details of drafting, intentional or not, often render content under one licence legally incompatible with content under a different one. An essential function of the limited set of Creative Commons licences is to forestall the hobbling impact that licence proliferation has on the network effect of open culture.

On my cynical days, I fear that this kind of hobbling is at the heart of a strategy to create 'open-access' licences just for scholarly publishers. These licences would reserve the most creative reuses for those who simply serve as the midwives for content, not for those who might go on to create works that can surprise, inform and delight. If we allow only a tiny set of predicted reuses, those are, by definition, the only reuses we will get - and they will benefit only the existing power players in scholarly publishing.

\section{SPECIOUS CONCERNS}

It is hard to precis all the specious concerns about why CC-BY will not work for scholarly publishing. In brief, those opposing the licence often claim that it: would allow others such as drug companies to sell works downstream; implies author endorsement of shady overlay journals; would require all the elements of an article to be freely licensed (including photographs, music, modern art and, presumably, Hollywood films); and would make attribution on text mining unwieldy.

CC-BY does indeed allow resale - of something that is already on the Internet for free. Anyone who pays for an object under CC-BY is either making a donation, or is paying a tax for being inept at searching the Internet. And a few key elements of CC-BY make it possible to prevent dastardly uses.

First, because attribution is up to the author and the journal, it is easy to make sure that any copy - if someone is trying to make a shady business of reprints, for instance - links back to the free version of the article.

Second, CC-BY does not grant publicity rights. That means that attribution can be used to clearly disclaim endorsement without

\section{LICENCE TO SHARE}

Leading open-access scholarly publishers have increasingly adopted CC-BY since its launch in 2002

100

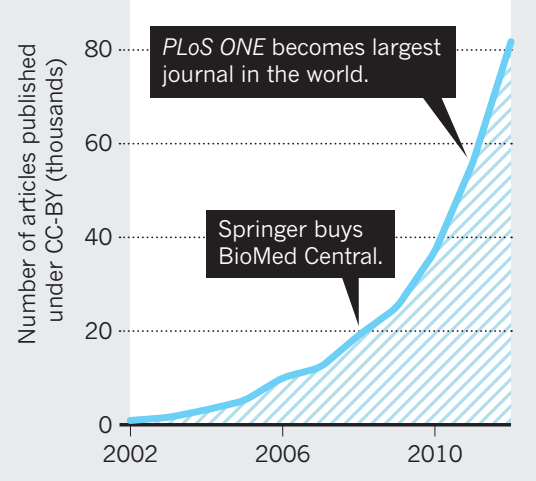

the tangles caused by commercial restrictions. The attribution can carry a requested form of citation, including the URL to the original, peer-reviewed, free and branded copy of the article. Then, anyone wishing to reprint must also reproduce that citation or be in violation of the copyright. It makes it hard to imply endorsement or sell something when the object itself carries the provenance, and links, to the free version in a trusted journal.

Similarly, publishers can communicate their desired attribution in a text-mining context. Indeed, because a text miner is only extracting 'facts' from the text, those facts are
"When in

doubt, use running code that someone else has already written." by law not covered by copyright - and thus not subject to the attribution requirement. Of course, from a technical and scientific perspective, readers will always want to know the provenance of a fact, and it is good practice to link back to the source. Indeed, the idea of link-based provenance is built into the design of the Semantic Web. It is a technical problem, not a legal one.

It is also easy to include in an article under a CC-BY licence items not subject to the licence - images, musical notation and more. That simply requires the rider "this article, unless otherwise noted, is available under CC-BY", and a note placed by the elements that are not available. Thus, a photograph under a Creative Commons licence can be used as one of Time magazine's Photos of the Year, for example, without rendering the rest of the publication subject to the terms of the licence.

In sum, the debate over CC-BY is actually an attempt to reinterpret what the 'open' in 'open access' means. There are parties who want open access to be as closed as possible to protect their business models from change.

A licence that is designed just for publishers might feel safer, but it is a fool's errand. CC-BY exists. It is used widely and is driving tens of millions of dollars in annual revenue for scholarly publishers such as BioMed Central, Hindawi and the Public Library of Science. It fulfils the community definitions of openness. And it works with the vast web of existing free content. For any new licence to achieve all that, it would need to be CC-BY.

It is encouraging that the open-access debate has moved from 'should we?' to 'how do we?', and that we're talking about the issue even in this august publication. It would be deeply sad if we were to fail now to draw on one of the basic lessons of the open movements that have come before: when in doubt, use running code that someone else has already written.

John Wilbanks is the chief commons officer at Sage Bionetworks in Seattle, Washington. e-mail: john.wilbanks@sagebase.org 